\title{
SOURCE PROCESS OF A DEEP-FOCUS EARTHQUAKE IN THE SEA OF OKHOTSK AS DEDUCED FROM LONG-PERIOD P AND SH WAVES
}

\author{
Tsutomu SASATANI \\ Department of Geophysics, Faculty of Science, \\ Hokkaido University, Sapporo, Japan
}

(Received June 17, 1974; Revised August 10, 1974)

\begin{abstract}
The source process of a deep-focus earthquake $(h=544 \mathrm{~km})$ of January 29,1971 in the Sea of Okhotsk is investigated on the basis of the primary P and SH pulses, which are deduced from the WWSSN long-period seismic signals after eliminating the influence of the seismograph, crust and mantle by the deconvolution technique. The shape of the primary $\mathrm{P}$ and SH pulses is characterized by a uni-directional, single pulse. The pulse widths of these primary pulses vary depending on the location of stations. The pulse width of the primary SH pulses is comparable to that of the primary $\mathbf{P}$ pulses at stations placed in nearly the same azimuth and having nearly the same epicentral distance. These results strongly suggest that the earthquake occurred in the form of shear faulting, the model of which was inferred to be a uni-lateral propagating fault. In the deduction of this inference, the primary SH pulses especially played an important role. Source parameters for the present earthquake are determined by comparing the theoretical $\mathbf{P}$ and SH wave displacements directly with the primary $\mathbf{P}$ and $\mathbf{S H}$ pulses. Seismic moment $M o$, rupture velocity $v$, fault length $L$, fault width $W$, displacement discontinuity $D$ and stress drop $\Delta \sigma$ determined are as follows: $M o=2.8 \times 10^{26}$ dyne. $\mathrm{cm}, v=4.5 \mathrm{~km} / \mathrm{sec}, L=20 \mathrm{~km}, W=10 \mathrm{~km}, D=1.2 \mathrm{~m}$ and $\Delta \sigma=240$ bars.
\end{abstract}

\section{Introduction}

In order to clarify the properties of the descending lithosphere, it is important to derive the source dimension, rupture velocity and the stress drop for deep-focus earthquakes. Several attempts to obtain such quantities have been made by many authors (HONDA, 1951; KASAHARA, 1963; TENG and BENMeNAHEM, 1965; BerckHEMER and JACOB, 1968; Bollinger, 1968; KHATtri, 1969; Mikumo, 1969, 1971a, b; Chandra, 1970; Fukao, 1970, 1972; Wyss, 1970; Wyss and Molnar, 1972; Oike, 1969; ABe, 1972; Linde and SACKs, 1972; Sasatani, 1974).

Teng and Ben-Menahem (1965), Khattri (1969), Wyss and Molnar (1972) and LINDE and SACKS (1972) have inferred the source time function, 
source dimension, rupture velocity and the stress drop from the spectra of the observed seismic signals. However, it is difficult to derive such source parameters independently from the amplitude and phase spectra of the observed seismic signals, since these spectra inseparably include the effect of the source time function and the effect of the source finiteness.

As an alternative to the method based on the spectral analysis, Mrkumo $(1969,1971 \mathrm{a}, \mathrm{b})$, FuKAo (1970) and SASATANI (1974) have presented the method of the analysis of the observed seismic signals in the time domain. The method of this analysis consists of two steps: constructing synthetic seismograms of $\mathbf{P}$ and $\mathrm{S}$ waves from an appropriately assumed source model and comparing these seismograms with the observed ones. The synthetic seismograms, however, are not so sensitive to the some source parameters as Mikumo (1969) and SASATANI (1973) have pointed out. They estimated the source parameters by assuming a rupture velocity or a fault width.

More direct method to estimate the source parameters from the analysis of the waveform of $\mathrm{P}$ and $\mathrm{S}$ wave displacements has been presented by BerCKHEMER and JACOB (1968) and FuKAo (1972). They deduced the primary $\mathrm{P}$ pulses equalized near the source region by the deconvolution technique. The primary $\mathrm{P}$ pulse represents the $\mathrm{P}$ wave displacement at unit distance from the origin in a homogeneous and infinite medium. According to this method, the primary $\mathbf{P}$ pulses can be compared directly with the theoretical $\mathbf{P}$ wave displacements calculated for the source model in a homogeneous and infinite medium. The $\mathbf{P}$ wave displacement in a homogeneous and infinite medium is extremely sensitive to the source parameters. This is of great advantage to this method.

In this paper, the primary $S$ pulses as well as the primary $P$ pulses will be deduced from the observed seismic signals by the deconvolution technique and they will be employed to investigate the source process of the deep-focus earthquake. It will be shown that the primary $S$ pulses provide the key to the selection of a source model and a fault plane.

\section{Data}

The earthquake studied here occurred in the Sea of Okhotsk on January 29, 1971. The epicentral coordinate and the origin time, given by the U.S.N.O.A.A. are as follows: epicenter, $51.7^{\circ} \mathrm{N}, 150.9^{\circ} \mathrm{E}$; depth, $544 \mathrm{~km}$, origin time, $21^{\mathrm{h}} 58^{\mathrm{m}} 5.40^{\mathrm{s}}$. The earthquake had a magnitude $m b$ of 6.1 .

The seismic body wave signals recorded on long-period WWSSN seismograph were used. The focal mechanism solution of this earthquake was determined using long-period $\mathrm{P}$ and $\mathrm{pP}$ phases and $\mathrm{S}$ wave polarization angles. The solution is illustrated in Fig. 1 using the equal area projection of the lower 

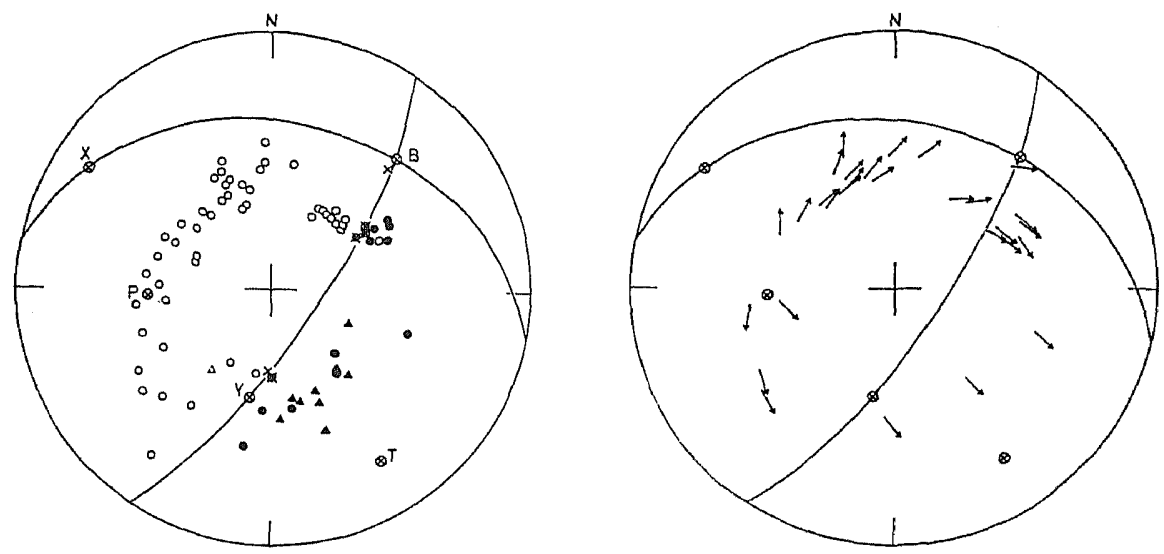

Fig. 1. Focal mechanism solution of the deep-focus earthquake of January 29,1971 in the Sea of Okhotsk. The radiation patterns of $\mathrm{P}$ and $\mathrm{pP}$ first motions (left) and $S$ wave polarization angles (right) are projected onto the lower half of the focal sphere using equal area projection. Closed symbols and open symbols indicate the compressions and the dilatations. Circles and triangles refer to $\mathbf{P}$ and $\mathrm{pP}$ phases. $\times$ indicates the stations judged to be near a nodal line in the radiation pattern from the character of the signals. Arrows indicate the $S$ wave polarization angles. $\mathrm{P}$ and $\mathrm{T}$ indicate the compressional and tensional axes.

half of the focal sphere. Two nodal planes of $\mathrm{P}$ wave are given by the dip direction of $\mathrm{N} 9.0^{\circ} \mathrm{E}$, the dip angle of $32.4^{\circ}$, and the dip direction of $\mathrm{N} 124.0^{\circ} \mathrm{E}$, the dip angle of $75.0^{\circ}$, respectively. The pattern of $\mathrm{S}$ wave polarization angles represents a double couple type source. The standard deviation of the $S$ wave polarization angle from the expected value was $18.1^{\circ}$.

\section{Deconvolution of long-period $P$ waves}

The seismic body waves radiated from the source are distorted in the earth's mantle and crust, and finally, by the seismograph. The influence of this transmitting system was eliminated by the deconvolution technique to recover the primary $\mathbf{P}$ pulses from the long-period records. If the earth is idealized as a linear system, the observed $\mathrm{P}$ wave signal $g(t)$ can be represented by a convolution integral as follows (BERCKHEMEr and JACOB, 1968; FuKAo, 1972):

$$
g(t)=\int_{-\infty}^{\infty} h(\tau) f(t-\tau) \mathrm{d} \tau,
$$

where $h(t)$ is the impulse response of the earth-seismograph system and $f(t)$ is the primary $\mathrm{P}$ pulse. The primary $\mathrm{P}$ pulse $f(t)$ is, therefore, given by the deconvolution of $g(t)$ : 


$$
f(t)=\frac{1}{2 \pi} \int_{-\infty}^{\infty} H^{-1}(\omega) G(\omega) \mathrm{e}^{i \omega t} \mathrm{~d} \omega
$$

where $G(\omega)$ and $H(\omega)$ are the Fourier transforms of $g(t)$ and $h(t)$, respectively. According to Teng and Ben-Menahem (1965), $H(\omega)$ is given by

$$
H(\omega)=G H_{\mathrm{AT}}(\omega) H_{\mathrm{CR}}(\omega) H_{\mathrm{INS}}(\omega),
$$

where $G$ is the geometrical spreading factor which is independent of the frequency, and $H_{\mathrm{AT}}(\omega), H_{\mathrm{CR}}(\omega)$ and $H_{\mathrm{INS}}(\omega)$ are the complex transfer functions for the attenuation in the mantle, the crust and the instrument, respectively. Computations of the geometrical spreading and the attenuation were made on the basis of the JEFFREYS-Bullen velocity model and the $Q_{\mathrm{P}}$ model in the mantle obtained by MIKumo and KuRITA (1968). The transfer function $H_{\mathrm{CR}}(\omega)$ for a layered crust was calculated by HASKELL's method (1962), assuming that the crustal structure is the same for all stations as the crustal model employed by FuKao (1970). The transfer function $H_{\mathrm{INS}}(\omega)$ for the instrument was calculated according to HAGIWARA's formula (1958). In this calculation, it was taken that $T_{\mathrm{p}}=15 \mathrm{sec}, T_{\mathrm{g}}=100 \mathrm{sec}, h_{\mathrm{p}}=1.0, h_{\mathrm{g}}=1.0$ and $\sigma=0.15$ for the longperiod WWSSN seismograph, where $T, h$ and $\sigma$ indicate the free period, the

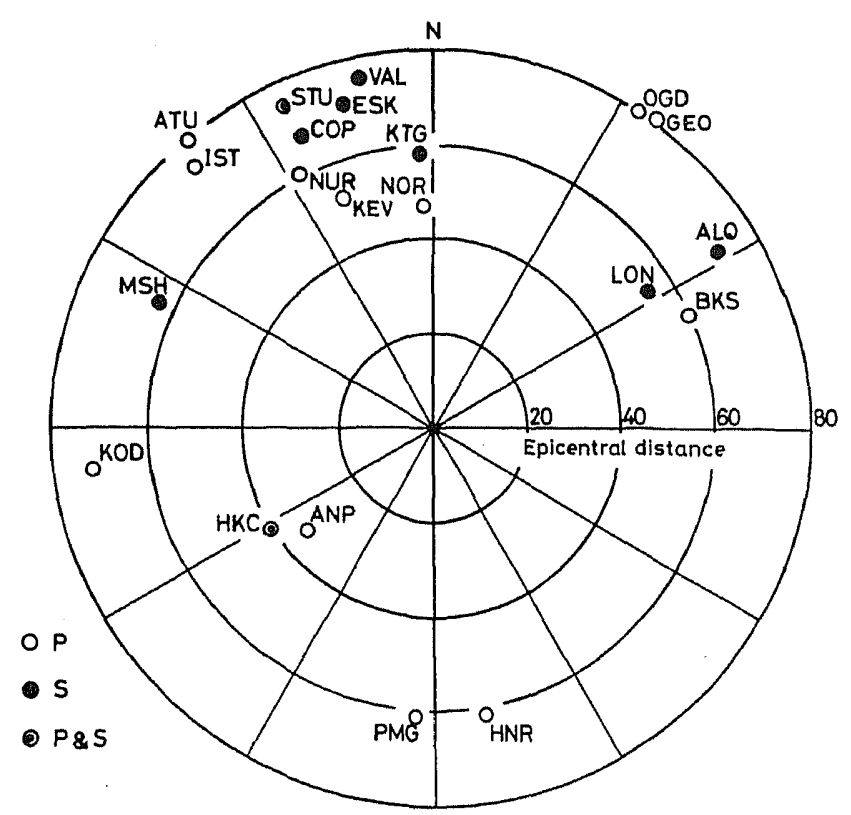

Fig. 2. Spatial distribution of stations referred to the epicenter. The stations which are entered into analysis of the deconvolution of $\mathrm{P}$ wave, $\mathrm{SH}$ wave and both waves are indicated by open, filled and double circles, respectively. 

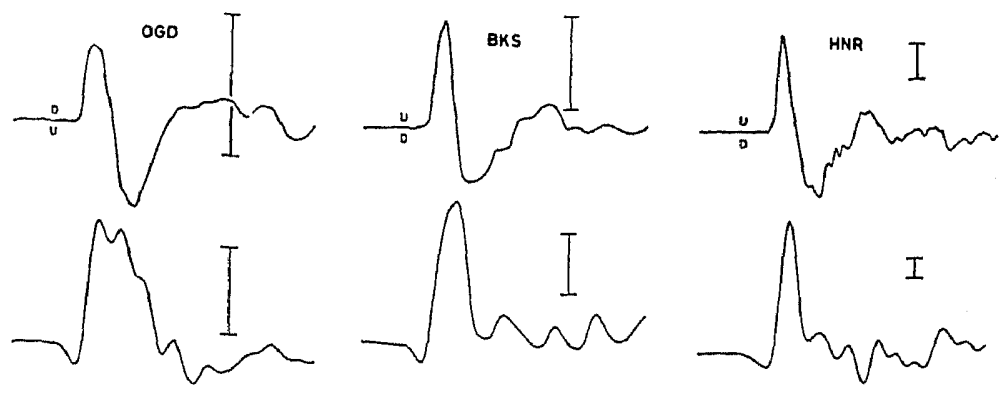<smiles>CCCCCCCCC</smiles>
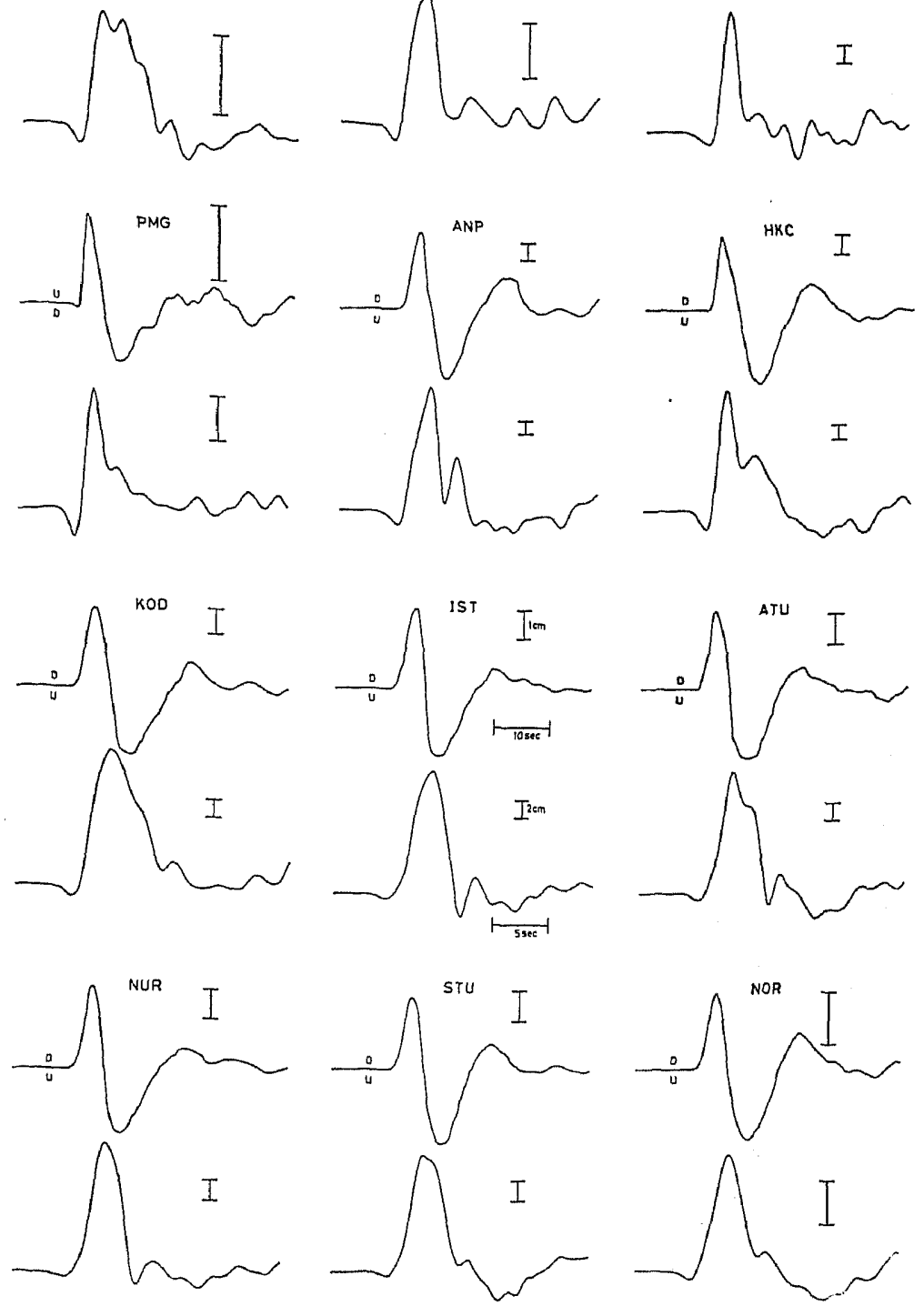

Fig. 3. Upper set: Vertical component of the observed $P$ wave signals, equalized to a magnification of 1500 . Lower set: Primary $P$ pulses deduced from the observed $P$ wave signals by the deconvolution technique. Note that the time scale is two times larger than that of upper set. 
damping constant and the coupling constant, respectively and the subscript $\mathrm{p}$ and $\mathrm{g}$ refer to the pendulum and the galvanometer.

The whole long-period $\mathrm{P}$ wave signal was entered into analysis if it was large and clear and had a high signal-to-noise ratio. As shown in Fig. 2, fourteen stations were selected. The signals at these stations were digitized at an interval of $0.4 \mathrm{sec}$. The time window of $70 \mathrm{sec}$ was generally used in the analysis. The complex Fourier spectra of these signals were computed by a fast Fourier transform program and corrected for the seismograph response, the crustal effect at station, the geometrical spreading and the attenuation in the mantle. The spectra thus obtained were high-cut filtered since the spectrum in the short-period range is considered to have been significantly affected by the presence of seismic noise and by the detail of the layered crustal structure (BERCKHEMER and $\mathrm{J}_{\mathrm{ACOB}}, 1968$ ). The filter was designed so that it had constant amplification at period longer than $5 \mathrm{sec}$ and zero amplification at and above the Nyquist frequency. According to Fukao (1972), the effect of the high-cut filtering designed above was negligibly small. The present

Table 1. Pulse width of the primary $\mathrm{P}$ and SH pulses, and seismic moment.

\begin{tabular}{|c|c|c|c|c|c|}
\hline Station code & $\mathrm{Az}$, degree & $\Delta$, degree & $T_{\mathrm{P}}, \mathrm{sec}$ & $T_{\mathrm{SH}}, \mathrm{sec}$ & $M o \times 10^{26}$ dyne $\cdot \mathrm{cm}$ \\
\hline OGD & 33.25 & 79.51 & 5.6 & - & 2.44 \\
\hline GEO & 35.95 & 80.56 & 6.2 & - & 4.21 \\
\hline $\mathrm{LON}$ & 58.13 & 53.98 & - & 4.8 & - \\
\hline ALQ & 58.25 & 70.50 & - & 5.0 & - \\
\hline $\mathrm{BKS}$ & 66.28 & 59.68 & 3.9 & - & $5.01 *$ \\
\hline HNR & 169.82 & 61.37 & 2.5 & - & 2.08 \\
\hline PMG & 184.23 & 60.93 & 2.6 & - & $1.80 *$ \\
\hline ANP & 231.41 & 34.65 & 3.8 & - & 3.17 \\
\hline $\mathrm{HKC}$ & 237.99 & 40.77 & 2.9 & 3.0 & 1.68 \\
\hline KOD & 263.35 & 71.76 & 6.3 & - & 2.89 \\
\hline MSH & 295.27 & 63.26 & - & 5.3 & - \\
\hline IST & 318.26 & 74.75 & 5.2 & - & 2.71 \\
\hline ATU & 320.15 & 79.50 & 5.2 & - & 2.69 \\
\hline NUR & 332.58 & 60.14 & 4.6 & - & 3.04 \\
\hline STU & 334.78 & 74.69 & 5.4 & $7.0 ?$ & 3.03 \\
\hline COP & 336.01 & 67.59 & - & 4.3 & - \\
\hline $\mathrm{KEV}$ & 338.53 & 52.21 & 4.6 & - & 3.02 \\
\hline ESK & 344.69 & 71.21 & - & 4.8 & - \\
\hline VAL & 348.06 & 75.54 & - & 5.0 & - \\
\hline $\mathrm{KTG}$ & 357.15 & 58.11 & - & 5.0 & - \\
\hline NOR & 357.51 & 46.80 & 4.9 & - & $4.04 *$ \\
\hline
\end{tabular}

$\mathrm{Az}$, epicenter to station azimuth; $\Delta$, epicentral distance; $T_{\mathrm{P}}$; pulse width of the primary P pulse; $T_{\mathrm{SH}}$, pulse width of the primary SH pulse; $M o$, seismic moment; *, seismic moment which is excluded from the calculation of the average value. 
author also confirmed this through the numerical model studies. The spectra thus obtained were inversely Fourier transformed according to Eq. (2). The final results represent the primary $P$ pulses.

The observed $\mathrm{P}$ wave signals and corresponding primary $\mathrm{P}$ pulses are shown in Fig. 3. The primary $P$ pulses were equalized at a distance $r=1 \mathrm{~km}$ near the source region, though it was only mathematical significance. The primary $P$ pulses at stations in the azimuth of $300^{\circ}-360^{\circ}$ (IST, ATU, STU, NUR, NOR) have nearly the same feature in the waveform and the pulse width. This strongly suggests that the primary pulse is not affected by the assumption in the calculation of deconvolution process, but it represents the actual source process.

Each primary $\mathrm{P}$ pulse is characterized by a uni-directional, single pulse, and the pulse shape is approximately trapezoidal. The pulse width of the primary $\mathbf{P}$ pulse varies from $2 \mathrm{sec}$ to $6 \mathrm{sec}$ depending on the location of stations (Table 1, Fig. 7). This shows that the source process of this earthquake had an azimuthal dependence.

The shorter period oscillation in the primary $\mathrm{P}$ pulse at station OGD was caused by the background seismic noise. A small second peak appears in the primary $\mathbf{P}$ pulse at stations $\mathrm{ANP}$ and $\mathrm{HKC}$, but it does not appear in the primary $P$ pulse at other stations. Although this second peak may correspond to the second event, it was regarded not as a signal, but as a seismic noise in this study. The pulse width of these primary $\mathrm{P}$ pulses was measured for the first pulse only.

\section{Deconvolution of Long-Period S Waves}

KaSAHARA (1963) has deduced the ground motions of long-period S wave from seismograms of several deep-focus earthquakes recorded at Matsushiro, Japan by using the analog computer. He investigated the source process of these earthquakes based on a single record. Thus, he could not clarify whether there was an azimuthal effect in waveform of the ground motion of long-period $S$ wave. Since the ground motions were obtained after eliminating the influence of the seismograph alone, they contained the influence of the crustal layering and the attenuation in the mantle.

This paper is the first attempt to deduce the primary $\mathbf{S}$ pulses equalized near the source region by the deconvolution technique. Nine stations were selected for this attempt as shown in Fig. 2. To avoid the effect of the contamination by the later arrivals, the $S$ wave signals recorded at stations with the epicentral distance $40^{\circ}$ to $70^{\circ}$ were mainly used (Table 1). Unfortunately, we could not trace completely the $S$ wave seismograms recorded at stations in the azimuth of about $180^{\circ}$ because of the signals being out of scale. 
Seismograms of the NS- and EW-components of S wave were digitized at an interval of $0.6 \mathrm{sec}$, and they were resolved into SH and SV waves. Computation of the deconvolution of SH and SV waves is essentially the same as that of $\mathrm{P}$ waves. The geometrical spreading, attenuation and the crustal response appropriated to $\mathrm{SH}$ and $\mathrm{SV}$ waves were computed on the basis of the models used in the deconvolution of $\mathrm{P}$ waves. For a mantle $Q_{\mathrm{S}}$ model, it was assumed that $Q_{\mathrm{P}}=2 Q_{\mathrm{S}}$ at all depths.

The observed $\mathrm{SH}$ waves and corresponding primary $\mathrm{SH}$ pulses equalized at a distance $r=1 \mathrm{~km}$ are shown in Fig. 4. A weak trough preceding each
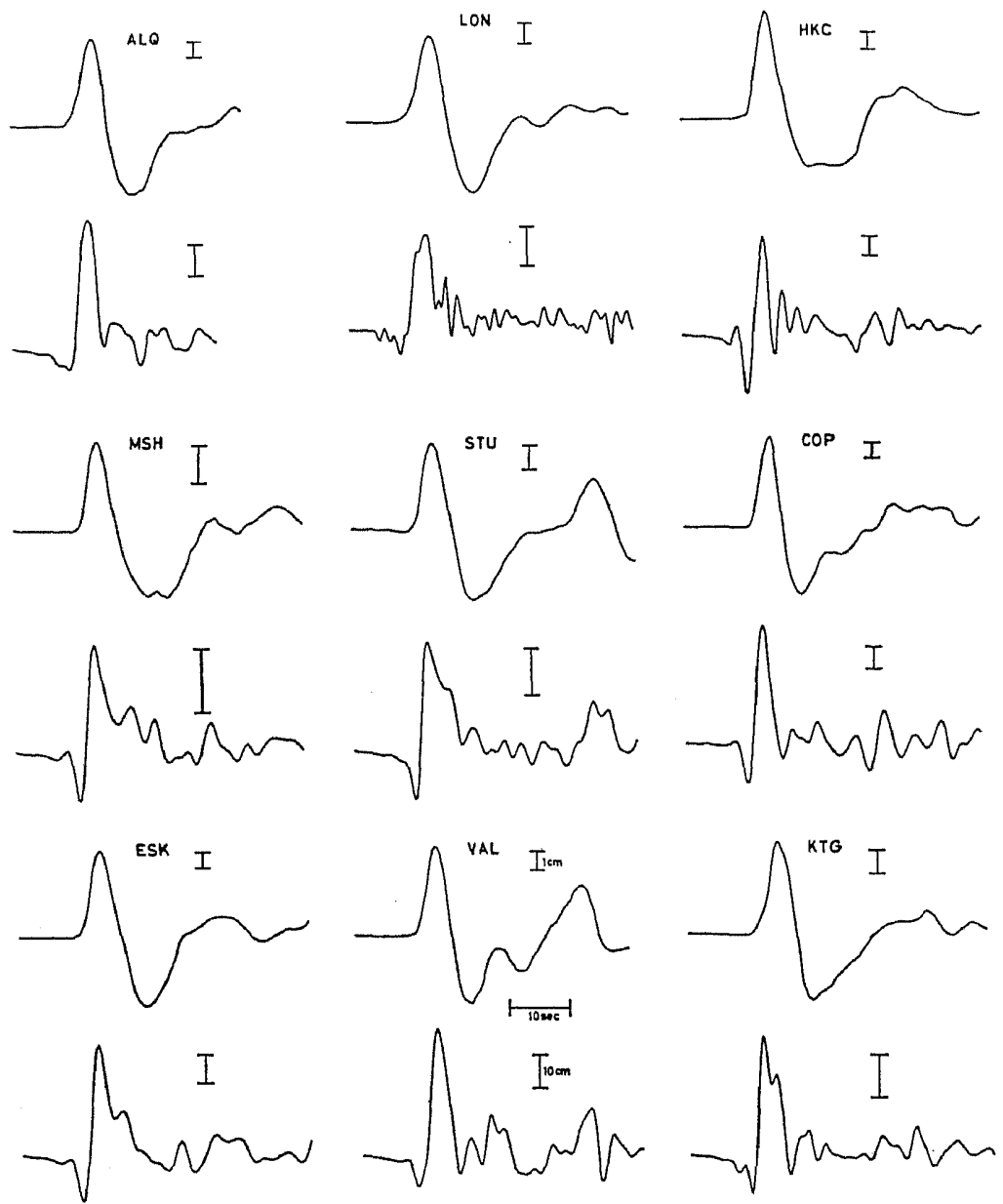

Fig. 4. Upper set: Observed SH wave signals, equalized to a magnification of 1500 . Lower set: Primary SH pulses deduced from the observed SH wave signals by the deconvolution technique. The length of the bars representes the vertical scale as shown at station VAL for both sets. 
primary SH pulse might be due to the error of the base line in the digitizing process. Although the primary SH pulse is contaminated by the seismic noise, each primary SH pulse is characterized by a uni-directional, single pulse and the pulse shape is approximately trapezoidal, that is the same as the primary $P$ pulse. The pulse width of the primary SH pulses varies from $3 \mathrm{sec}$ to $5 \mathrm{sec}$ depending on the location of stations (Table 1, Fig. 7). This shows that the source process of this earthquake had an azimuthal dependence as indicated in the previous section. In the observational seismology, it has been often pointed out that predominant period of $\mathbf{S}$ waves is longer than that of $\mathrm{P}$ waves (FURUYA, 1969; LINDE and SACKs, 1972). The pulse width of the primary SH pulses of this earthquake, however, is comparable to that of the primary $\mathbf{P}$ pulses at stations placed in nearly the same azimuth and having nearly the same epicentral distance (Table 1). It must be noted that the pulse width of $\mathrm{SH}$ pulses is not always longer than that of $\mathrm{P}$ pulses.

Since the SV waves were contaminated by the seismic noise, the corresponding primary SV pulses were complex and different from the primary SH pulses. This may be due to the effect of the crustal structure near station. For this reason, we shall proceed to the following discussion only for the primary $\mathrm{P}$ and $\mathrm{SH}$ pulses.

\section{Model of the Source}

For the deep-focus earthquake, various source models have been studied in the theoretical and observational aspects by many authors. The far-field displacement, the relation of $T_{\mathrm{P}}$ or $T_{\mathrm{S}}$ and $\cos \theta$, and the relation of $T_{\mathrm{P}}$ and $T_{\mathrm{s}}$ for the uni-lateral propagating fault, bi-lateral propagating fault, circular fault and the cavity model are summarized schematically in Fig. $5 ; T_{\mathrm{P}}$ and $T_{\mathrm{S}}$ indicate the pulse width of $\mathrm{P}$ and $\mathrm{S}$ pulses and $\theta$ indicates the angle between the ray leaving the focus and the vector of the rupture propagation. These are obtained by assuming that the time dependence of dislocation is a step function. However, if the time dependence of dislocation is different from a step function, above relations are maintained as far as it is not very far from a step function.

The waveforms of the displacements from these various source models are different each other as shown in Fig. 5. For the uni-lateral propagating fault, the waveform of the displacement is trapezoidal, $T_{\mathrm{P}}$ and $T_{\mathrm{S}}$ have an azimuthal dependence, and $T_{\mathrm{S}}$ is not always longer than $T_{\mathrm{P}}$ at a given station. $T_{\mathrm{P}}$ is longer than $T_{\mathrm{S}}$ for $\operatorname{con} \theta>0$ and $T_{\mathrm{P}}$ is shorter than $T_{\mathrm{S}}$ for $\cos \theta<0$ (HIRASA WA and StAUder, 1965; SAVAGe, 1965). For the bi-lateral propagating fault and the circular fault, $T_{\mathrm{P}}$ and $T_{\mathrm{S}}$ have an azimuthal dependence, which is different from that for the uni-lateral propagating fault, and $T_{\mathrm{S}}$ is 


\begin{tabular}{|c|c|c|c|c|}
\hline $\begin{array}{l}\text { Model of } \\
\text { the source }\end{array}$ & $\begin{array}{l}\text { Geometry of } \\
\text { the source }\end{array}$ & $\begin{array}{l}\text { Far-field } \\
\quad \text { displacement }\end{array}$ & $\begin{array}{l}\text { Relation between } \\
\text { Tp.Ts and } \cos \theta\end{array}$ & $\begin{array}{l}\text { Relation between } \\
\text { Tp and Ts }\end{array}$ \\
\hline $\begin{array}{l}\text { Uni-lateral } \\
\text { propagating } \\
\text { fault }\end{array}$ & & & $\frac{1}{\cos \theta}$ & $\begin{array}{l}T p>T s \\
\text { for } \cos \theta>0 \\
T p<T s \\
\text { for } \cos \theta<0\end{array}$ \\
\hline $\begin{array}{l}\text { Bi-lateral } \\
\text { propagating } \\
\text { fault }\end{array}$ & & & & $T p<T s$ \\
\hline Circular fault & & & & $T p<T s$ \\
\hline Cavity model & & & & $T p<T s$ \\
\hline
\end{tabular}

Fig. 5. Schematic illustration of the far-field displacements, the relation between $T_{\mathrm{P}}$ or $T_{\mathrm{S}}$ and $\cos \theta$ and the relation between $T_{\mathrm{P}}$ and $T_{\mathrm{S}}$ for various source models of deep-focus earthquakes. $T_{\mathrm{P}}$ and $T_{\mathrm{S}}$ indicate the pulse width of $\mathrm{P}$ and $\mathrm{S}$ waves. $\theta$ indicate the angle between the ray leaving the focus and the vector of the rupture propagation.

always longer than $T_{\mathrm{P}}$ at any given station (HIRASAWA and STAUDER, 1965; SAVAGE, 1966). For the cavity model, $T_{\mathrm{P}}$ and $T_{\mathrm{S}}$ have no azimuthal dependence and $T_{\mathrm{S}}$ is always longer than $T_{\mathrm{P}}$ at any given station (HoNDA, 1959; Hirasawa and Sato, 1963; Koyama et al., 1973).

The results obtained in the previous sections 3, 4 are as follows: (1) The primary $\mathrm{P}$ and $\mathrm{SH}$ pulses are characterized by a uni-directional, single pulse and the pulse shape is approximately trapezoidal; (2) The pulse widths of them show an azimuthal dependence (see Fig. 7); (3) The pulse width of the primary SH pulses is comparable to that of the primary $\mathrm{P}$ pulses at stations placed in nearly the same azimuth and having nearly the same epicentral distance (Table 1). Comparing these results with the predicted relations for various source models mentioned above, it is strongly suggested that the source model of this earthquake is a uni-lateral propagating fault. These results are not predicted from the source models other than the uni-lateral propagating fault. Without the data for the primary SH pulses, it is difficult to distinguish the uni-lateral propagating fault from the bi-lateral propagating fault and the circular fault based on the pulse widths, because these source models equally show an azimuthal dependence of the pulse widths. The primary SH pulses provided the key to the selection of a source model.

We shall infer the fault dimension and the rupture velocity from analysis 
of the primary $\mathbf{P}$ and $\mathrm{SH}$ pulses. Let the line source propagates with a constant rupture velocity $v$. The line segment of the source is $W$ and inclining at the angle $\gamma$ from the $z$-axis in the plane $x=0$. The final length of the fault is $L$ (Fig. 6). It is assumed that the dislocation occurs instantaneously, that is,
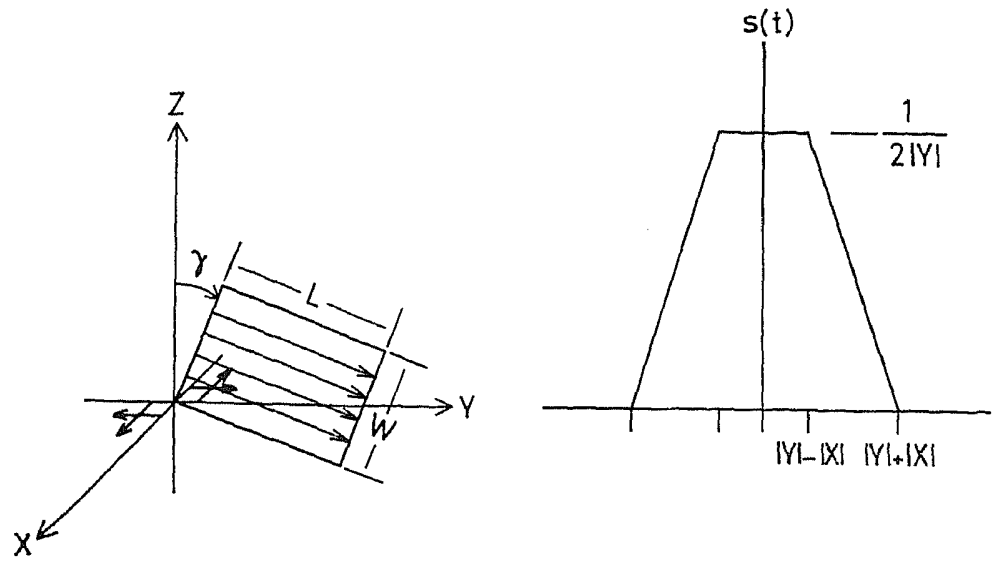

Fig. 6. Geometry of the source (left) and waveform of $P$ or $S$ wave displacement (right). The function $s(t), X$ and $Y$ are expressed by equations (5) and (6) in the text.

stepwise. We introduce the spherical coordinate system $(r, \theta, \varphi)$ with the pole of the $y$-axis. The theoretical $\mathrm{P}$ and $\mathrm{SH}$ wave displacements for this fault model can be obtained by the method by Hirasawa and STauder (1965). The displacements are given by Eq. (4).

$$
U_{\mathrm{P}, \mathrm{S}}(t)=\frac{M o}{4 \pi \rho} \frac{1}{v_{\mathrm{P}, \mathrm{S}}^{3}} \frac{R_{\mathrm{P}, \mathrm{S}}}{r} s(t)
$$

where $U_{P, \mathrm{~S}}(t)$ is the displacement of $\mathrm{P}$ or $\mathrm{S}$ wave, Mo is the total seismic moment, $\rho$ is the density, $v_{\mathrm{P}, \mathrm{S}}$ is the $\mathrm{P}$ - or $\mathrm{S}$-wave velocity, $R_{\mathrm{P}, \mathrm{S}}$ is the radiation pattern coefficient for $\mathrm{P}$ or $\mathrm{S}$ wave and $r$ is the distance from the focus. The function $s(t)$ is written as

$$
\begin{aligned}
& s(t)=\frac{1}{2\left|Y_{\mathrm{P}, \mathrm{S}}\right|} \quad \text { for } \quad|t| \leqq\left|Y_{\mathrm{P}, \mathrm{S}}\right|-\left|X_{\mathrm{P}, \mathrm{S}}\right| \\
& =\frac{\mp t+\left|X_{\mathrm{P}, \mathrm{S}}\right|+\left|Y_{\mathrm{P}, \mathrm{S}}\right|}{4\left|X_{\mathrm{P}, \mathrm{S}}\right|\left|Y_{\mathrm{P}, \mathrm{S}}\right|} \quad \text { for } \mp: t \gtrless 0 \text {, } \\
& \left|Y_{\mathrm{P}, \mathrm{S}}\right|-\left|X_{\mathrm{P}, \mathrm{S}}\right| \leqq|t| \leqq\left|Y_{\mathrm{P}, \mathrm{S}}\right|+\left|X_{\mathrm{P}, \mathrm{S}}\right| \\
& =0 \quad \text { for }|t| \geqq\left|Y_{\mathrm{P}, \mathrm{S}}\right|+\left|X_{\mathrm{P}, \mathrm{S}}\right|
\end{aligned}
$$

where 


$$
\begin{aligned}
& X_{\mathrm{P}, \mathrm{S}}=\frac{W}{2 v_{\mathrm{P}, \mathrm{S}}}(-\cos \theta \sin \gamma+\sin \theta \sin \varphi \cos \gamma) \\
& Y_{\mathrm{P}, \mathrm{S}}=\frac{L}{2}\left[\frac{1}{v}-\frac{1}{v_{\mathrm{P}, \mathrm{S}}}(\cos \theta \cos \gamma+\sin \theta \sin \varphi \sin \gamma)\right]
\end{aligned}
$$

The function $s(t)$ is illustrated in Fig. 6. The pulse widths of the function $s(t)$ are shown to be of shortest time duration for azimuth in the direction of fault propagation and of longest duration for opposite azimuth from Eq. (5), (6).

In Fig. 7 is illustrated the spatial distribution of the pulse widths of the primary $\mathrm{P}$ and $\mathrm{SH}$ pulses. The pulse widths are projected onto the lower half of the focal sphere using equal area projection together with the focal mechanism solution. As is clearly seen, the pulse width is smaller near the $Y$-axis for both the primary $\mathbf{P}$ and $\mathrm{SH}$ pulses. From the character of the function $s(t)$ mentioned above, this suggests that the fault propagated in the direction of the $Y$-axis or the $-X$-axis. If the fault propagates in the direction of the $-X$-axis, the fault plane is the X-B plane and $T_{\mathrm{S}}$ must be longer than $T_{\mathrm{P}}$ for stations used in analysis because $\cos \theta<0$. This is not consistent with the result (3). If the fault propagates in the direction of the $Y$-axis, $T_{\mathrm{s}}$ is smaller than or nearly equal to $T_{\mathrm{P}}$ for stations used in analysis because $\cos \theta>0$. This is consistent with the result (3). From the above discussion, it is concluded that the fault propagated in the direction of the $Y$-axis and the fault plane is the plane with the dip direction of $\mathrm{N} 124^{\circ} \mathrm{E}$ and the dip angle of $75^{\circ}$,

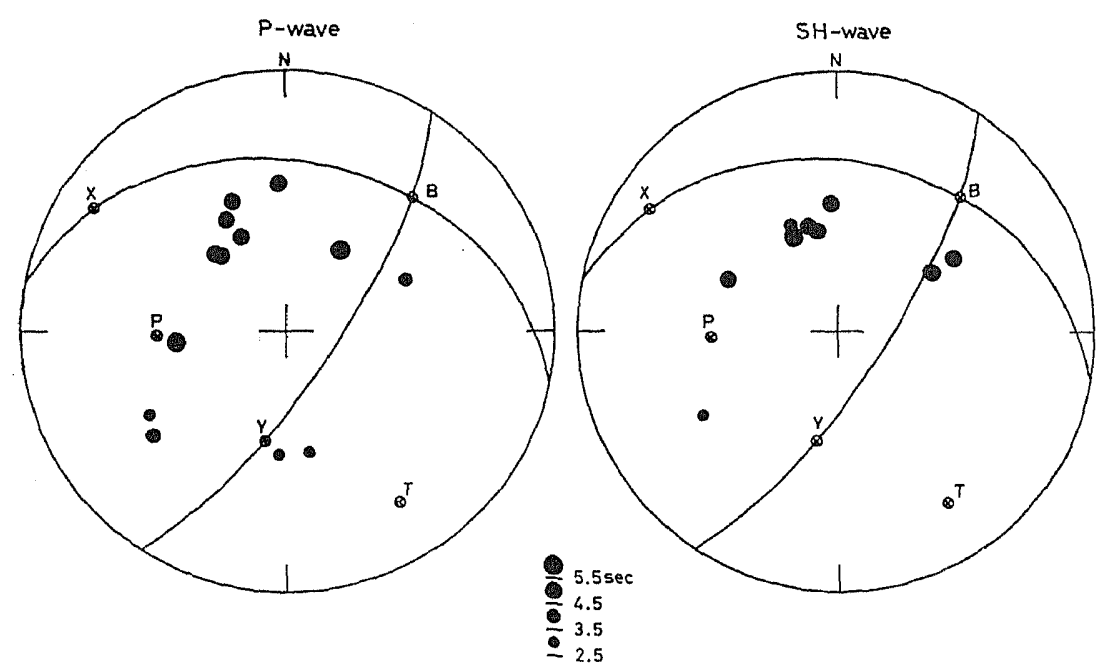

Fig. 7. Spatial distribution of the pulse widths of the primary $P$ pulses (left) and the primary SH pulses (right). The pulse widths are projected onto the lower half of the focal sphere using equal area projection, together with the focal mechanism solution. 
that is, the $Y$-B plane. Thus $\gamma=0$ in Eq. (6). The primary SH pulses provided the key to the selection of a fault plane.

Since the direction of the rupture propagation is constrained, the fault parameters to be determined are fault length $L$, fault width $W$ and rupture velocity $v$. We have calculated the theoretical $\mathrm{P}$ and $\mathrm{SH}$ wave displacements according to Eq. (4) for several combinations of the fault parameters $v, L, W$ to deduce the most probable values. In these calculations it was assumed that $v_{\mathrm{P}}=9.91 \mathrm{~km} / \mathrm{sec}, v_{\mathrm{S}}=5.46 \mathrm{~km} / \mathrm{sec}$ and $\rho=4.0 \mathrm{~g} / \mathrm{cm}^{3}$, respectively. The total seismic moment was estimated to be $2.8 \times 10^{26} \mathrm{dyne} . \mathrm{cm}$ in the next section. These theoretical $\mathrm{P}$ and $\mathrm{SH}$ wave displacements were compared with the primary $\mathrm{P}$ and $\mathrm{SH}$ pulses deduced from the actual records. The comparison is shown in Fig. 8 for stations IST and VAL. The good agreement between the theoretical displacements and the primary pulses is obtained not only for $\mathrm{P}$ wave but also for $\mathrm{SH}$ wave, when such fault parameters as $v=4.5 \mathrm{~km} / \mathrm{sec}$, $L=20 \mathrm{~km}$ and $W=10 \mathrm{~km}$ are adopted. The theoretical $\mathrm{P}$ and SH wave displacements calculated for the fault parameters other than those estimated above do not agree with the primary $\mathrm{P}$ and $\mathrm{SH}$ pulses. If the rupture velocity is as low as $3.0 \mathrm{~km} / \mathrm{sec}$, the pulse width of the theoretical displacements becomes too large compared with the primary pulses, and if the fault dimension

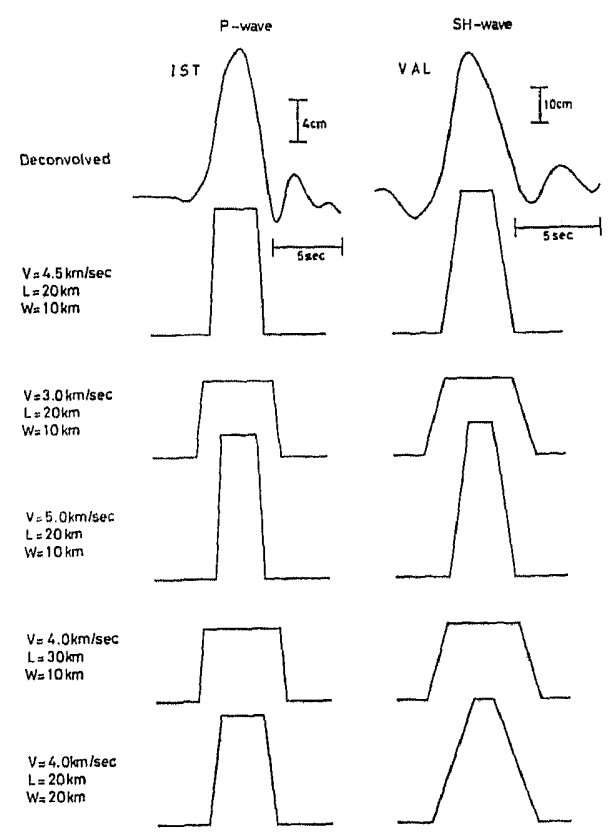

Fig. 8. Comparison between the primary $\mathbf{P}$ and SH pulses deduced from the records at stations IST and VAL, and the theoretical $\mathrm{P}$ and SH wave displacements radiated to IST and VAL for several combinations of the fault parameters $v, L, W$. 

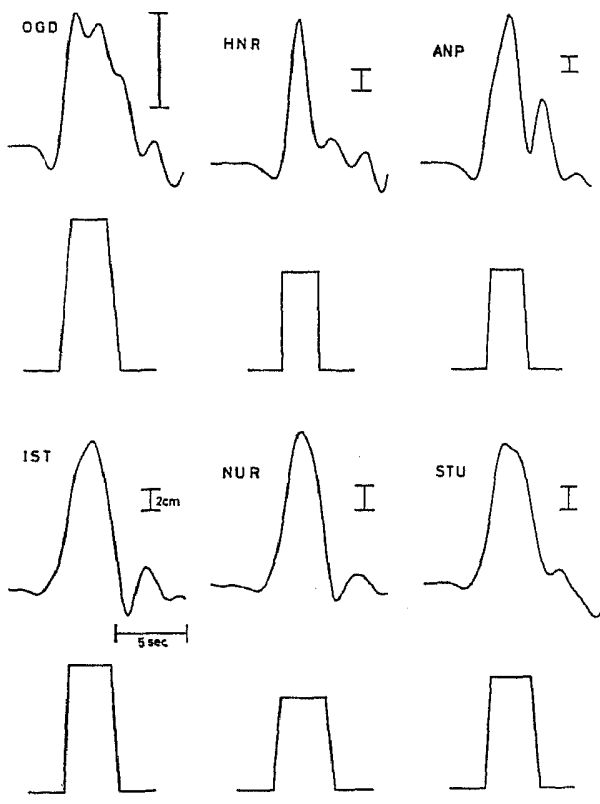

Fig. 9. Comparison between the primary $\mathbf{P}$ pulses (upper set) and the theoretical $\mathbf{P}$ wave displacements (lower set). The theoretical $P$ wave displacements were calculated for such fault parameters as $v=4.5 \mathrm{~km} / \mathrm{sec}, L=20 \mathrm{~km}$ and $W=10 \mathrm{~km}$.

is larger than that estimated above, the similar influence is exerted. If the rupture velocity is as high as $5.0 \mathrm{~km} / \mathrm{sec}$, the pulse width of the theoretical displacements becomes a little small compared with the primary pulses.

The theoretical $\mathbf{P}$ and $\mathrm{SH}$ wave displacements for other several stations calculated for the fault parameters estimated above are compared with the primary $\mathrm{P}$ and $\mathrm{SH}$ pulses in Fig. 9 ( $\mathrm{P}$ waves) and in Fig. 10 (SH waves). The satisfactory agreement on waveform, pulse height and pulse width between the theoretical displacements and the primary pulses was obtained except for SH pulse at station HKC. This leads to the following conclusions: the earthquake occurred in the form of shear faulting and the rupture propagated unilaterally; rupture velocity $v$ was $4.5 \mathrm{~km} / \mathrm{sec}$; fault length $L, 20 \mathrm{~km}$; fault width $W, 10 \mathrm{~km}$; and fault area $S, 200 \mathrm{~km}^{2}$. The theoretical $\mathrm{SH}$ wave displacement for station HKC shows a very sharp pulse whose width is about $2 \mathrm{sec}$. The deconvolution technique has not so high resolution for the such sharp pulse. This may be a reason for the discrepancy between the theoretical displacement and the primary pulse at station HKC.

\section{Source Parameters}

Total seismic moment $M o$ was calculated from the primary $\mathrm{P}$ pulse $f(t)$ 


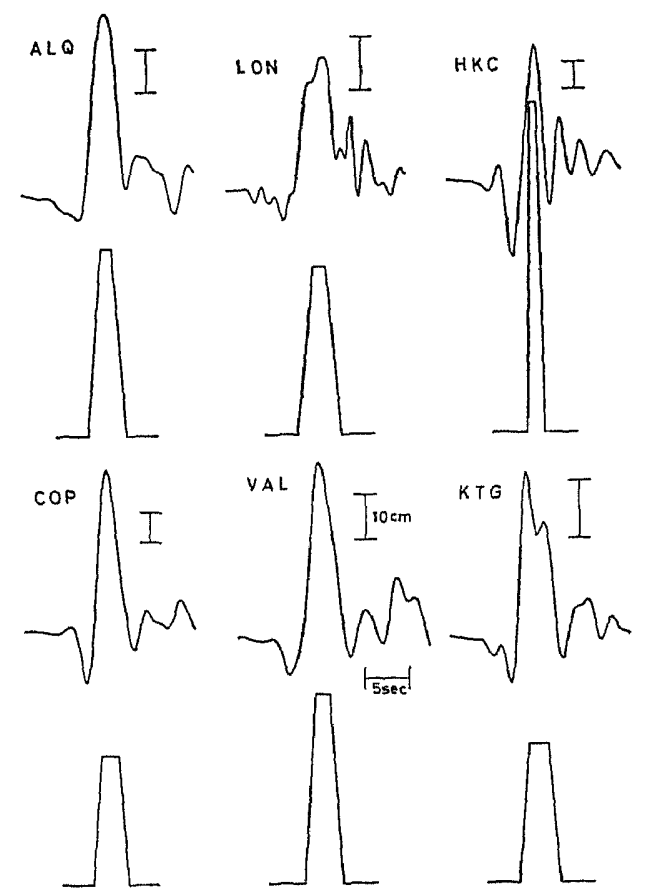

Fig. 10. Comparison between the primary SH pulses (upper set) and the theoretical SH wave displacements (lower set). The theoretical SH wave displacements were calculated for such fault parameters as $v=4.5 \mathrm{~km} / \mathrm{sec}, L=20 \mathrm{~km}$ and $W=10 \mathrm{~km}$.

at each station by using the following equation (BEBCKFEMER and JACOB, 1968; FUKAO, 1972).

$$
M o=4 \pi \rho v_{\mathrm{P}}^{3} r R_{\mathrm{P}}^{-1} \int f(t) \mathrm{d} t .
$$

The seismic moment obtained at each station is shown in Table 1 , and the average value was obtained as $2.8 \times 10^{26}$ dyne. $\mathrm{cm}$. In the calculation of this average value, the seismic moment obtained at stations near the nodal lines was excluded, because the radiation pattern coefficient for these stations is very sensitive to the accuracy of the determination of the focal mechanism solution.

The source parameters such as average dislocation $D$, stress drop $\Delta \sigma$ and strain drop $\varepsilon$ were determined from the total seismic moment and the fault dimension obtained in the previous section, by using a static dislocation theory. According to Eshelby (1957) and AKI (1966) these source parameters are related with the total seismic moment and the fault dimension as,

$$
M o=\mu D S, \quad \Delta \sigma=\frac{7}{16} \frac{M o}{a^{3}}, \quad \varepsilon=\frac{\Delta \sigma}{\mu},
$$


where $a=(S / \pi)^{1 / 2}$ is the radius of the circular fault, and $\mu$ is the rigidity. For simplicity, the fault surface is approximated by a circle of area $S$. The source parameters determined are as follows: average dislocation $D, 1.2 \mathrm{~m}$; stress drop $\Delta \sigma, 240$ bars; strain drop $\varepsilon, 2.0 \times 10^{-4}$. The rigidity was assumed to be $1.2 \times 10^{12}$ dyne $/ \mathrm{cm}^{2}$.

\section{Discussion and Conclusion}

The source process of a deep-focus earthquake in the Sea of Okhotsk was investigated on the basis of the primary $\mathrm{P}$ and $\mathrm{SH}$ pulses which were deduced from the observed seismic signals by the deconvolution. To obtain the source model of the deep-focus earthquake, no assumptions were made a priori, whereas the primary $\mathrm{P}$ and $\mathrm{SH}$ pulses were compared with the theoretical $\mathbf{P}$ and $\mathrm{SH}$ wave displacements predicted from the various source models. From this investigation, it was obtained that the earthquake occurred in the form of shear faulting, the model of which was inferred to be a uni-lateral propagating fault. This result is the same as those obtained by Fukao $(1970,1972)$ and Mikumo (1971a,b). We may conclude at this point that the primary SH pulses played an important role in deduction of above result.

FUKAO (1972) has investigated the deep-focus Western Brazil earthquake $(h=577 \mathrm{~km})$ of November 9,1963 , and obtained the rupture velocity as 2.2$2.5 \mathrm{~km} / \mathrm{sec}$, i.e., (0.4-0.5) $v_{\mathrm{s}}$. The rupture velocity of the earthquake analyzed in this paper was obtained to be $4.5 \mathrm{~km} / \mathrm{sec}$, i.e., $0.82 v_{\mathrm{s}}$, which is higher than that obtained by FUKAO (1972). Fukao has suggested that the small rupture velocity such as $v=(0.4-0.5) v_{\mathrm{s}}$ is a characteristic of deep-focus earthquakes. This, however, is not the case for the earthquake analyzed in this paper. In fact, if the rupture velocity is as low as $0.5 v_{\mathrm{S}}$, the pulse width of the theoretical displacements becomes too large and does not agree with that of the primary pulses (see Fig. 8). The difference between above two rupture velocities may represent the differences of the source process and/or the physical properties of the descending lithosphere. It is necessary to analyze much more deep earthquakes, to examine regional variation of rupture velocities.

On the other hand, OIKE (1969) has analyzed the multiple event of deep Banda Sea earthquake of June 22, $1966(h=507 \mathrm{~km})$ and obtained the rupture velocity of $4.6 \mathrm{~km} / \mathrm{sec}$, i.e., $0.87 v_{\mathrm{s}}$. CHANDRA (1970) also has analyzed the multiple event of the Peru-Bolivia border earthquake of August 15, 1963 $(h=543 \mathrm{~km})$ and obtained the rupture velocity of $4.7 \mathrm{~km} / \mathrm{sec}$, i.e., $0.86 v_{\mathrm{s}}$. These rupture velocities were obtained by dividing the distance between the two foci by the difference between the origin times of the two events. Fukao (1972) has indicated that the second event is not an instantaneous response to the arrival of the rupture but is a delayed response or an independent event, 
because an intermission of several second was observed between pulses corresponding to the first and the second events of these multiple events. Thus he suggested that the rupture velocities obtained by Orke (1969) and Chandra (1970) have no direct relation with the actual rupture velocity. Although CHANDRA (1973) has suggested that this interpretation is incorrect, the present author does not agree with Chandra's suggestion, but agree with Fukao's interpretation. The rupture velocity obtained in this paper is apparently the same as those obtained by OIKE (1969) and CHANDrA (1970), but this does not mean anything.

Generally a large shallow earthquake is followed by many aftershocks and its source dimension can be estimated from the distribution of these aftershocks, but this is not the case for the deep-focus earthquake. Then it is difficult to estimate the source dimension of the deep-focus earthquake. However, FUKAO (1972) has succeeded in estimating the source dimension of the deep-focus Western Brazil earthquake from the analysis of triple events. In this paper, the source dimension was estimated accurately by comparing the primary $\mathrm{P}$ and $\mathrm{SH}$ pulses with the theoretical $\mathrm{P}$ and $\mathrm{SH}$ wave displacements calculated for several combinations of the fault parameters. As a result of the investigation, it may be concluded that the source parameters obtained here are more reliable than those in the previous studies.

The stress drop obtained in this paper is similar to those obtained by Fukao $(1970,1972)$ and Mikumo $(1971 \mathrm{a}, \mathrm{b})$ and is remarkably larger than that for shallow earthquakes.

I wish to thank Dr. Ken Sudo for his encouragement and discussion throughout this work. I also thank Prof. T. Mikumo and Dr. H. Okada for critically reading the manuseript. The numerical calculations in this study were carried out by FACOM 230-60 at the Hokkaido University Computing Center.

\section{REFERENCES}

ABE, K., Focal process of the south Sandwich islands earthquake of May 26, 1964, P/tys. Earth Planet. Interiors, 5, 110-122, 1972.

AKI, K., Generation and propagation of $\mathrm{G}$ waves from the Niigata earthquake of June 16 , 1964. Part 2. Estimation of earthquake moment, released energy, and stress-strain drop from the G wave spectrum, Bull. Earthq. Res. Inst., 44, 73-88, 1966.

BerCKhemer, $\mathrm{H}$. and $\mathrm{K}$. H. $\mathrm{J}_{\mathrm{ACOB}}$, Investigation of the dynamical process in earthquake foci by analyzing the pulse shape of body waves, Proc. Xth Assembly, ESC II, 253-352, 1968.

BOLLINGER, G. A., Determination of earthquake fault parameters from long-period $P$ waves, J. Geophys. Res., 73, 785-807, 1968.

Chandra, U., The Peru-Bolivia border earthquake of August 15, 1963, Bull. Seism. Soc. Amer., 60, 639-646, 1970.

CHANDRA, U., Source processes of a large deep-focus earthquake and its tectonic implications -The Western Brazil earthquake of 1963: Comments, Phys. Earth Planet. Interiors, 7, 115-121, 1973. 
ESHELBY, J. D., The determination of the elastic field of an ellipsoidal inclusion and related problems, Proc. Roy. Soc., London, A241, 376-396, 1957.

FUKaO, Y., Focal process of a deep focus earthquake as deduced from long-period $\mathrm{P}$ and $\mathrm{S}$ waves, Bull. Earthq. Res. Inst., 48, 707-727, 1970.

FUKAO, Y., Source process of a large deep-focus earthquake and its tectonic implication-The western Brazil earthquake of 1963, Phys. Earth Planet. Interiors, 5, 61-76, 1972.

FurUYA, I., Predominant period and magnitude, J. Phys. Earth, 17, 119-126, 1969.

HAGIWARA, T., A note on the theory of the electromagnetic seismograph, Bull. Earthq. Res., Inst., 36, 139-164, 1958.

HASkell, N. A., Crustal reflection of plane P and SV waves, J. Geophys. Res., 67, 4751-4765, 1962.

HrRasaWA, T. and R. Sato, Propagation of elastic waves from a spherical origin: Part 1 and 2, Zisin, 16, 52-77, 1963 (in Japanese).

Hirasawa, T. and W. Stauder, S. J., On the seismic body waves from a finite moving source, Bull. Seism. Soc. Amer., 55, 237-262, 1965.

Honda, H., Amplitudes of $\mathbf{P}$ and $\mathrm{S}$, magnitude and energy of deep earthquakes, Science Reports, Tohoku Univ., Ser. 5, Geophys., 3, 138-143, 1951.

HoNDA, H., The elastic waves generated from a spherical source, Science Reports, Tohoku Univ., Ser. 5, Geophys., 11, 178-183, 1959.

KASAHARA, K., Waveform analysis of S-pulse from deep-focus earthquakes. Part 1, Bull. Earthq. Res. Inst., 41, 209-216, 1963.

KHATTRI, K. N., Determination of earthquake fault plane, fault area and rupture velocity from the spectra of long-period P-waves and the amplitude of SH-waves, Bull. Seism. Soc. Amer., 59, 615-630, 1969.

Koyama, J., S. Horiuchi, ann T. HiRAsawa, Elastic waves generated from sudden vanishing of rigidity in a spherical region, J. Phys. Earth, 21, 213-226, 1973.

LINDE, A. T. and I. S. SACKs, Dimensions, energy, and stress release for south American deep earthquakes, J. Geophys. Res., 77, 1439-1451, 1972.

Mikumo, T., Long-period $P$ waveforms and the source mechanism of intermediate earthquakes, J. Phys. Earth, 17, 169-192, 1969.

Mikumo, T., Source process of deep and intermediate earthquakes as inferred from long-period $P$ and $S$ waveforms. 1. Intermediate depth earthquakes in the southwest Pacific region, J. Phys. Earth, 19, 1-19, 1971a.

Mikumo, T., Source process of deep and intermediate earthquakes as inferred from long-period $\mathrm{P}$ and $\mathrm{S}$ waveforms. 2. Deep-focus and intermediate earthquakes around Japan, J. Phys. Earth, 19 303-320, 1971b.

Mrkumo, T. and T. Kurita, Q distribution for long-period $\mathrm{P}$ waves in the mantle, J. Phys. Earth, 16, 11-29, 1968.

OIKE, K., The deep earthquake of June 22, 1966 in Banda Sea: A multiple shock, Bull. Disas. Prev. Res. Inst., Kyoto Univ., 19, 55-65, 1969.

SASATANI, $T$., Source process of earthquakes as deduced from long-period seismic body waves. 1. Distortion of long-period P waveforms, Geophys. Bull. Hokkaido Univ., 29, 1-16, 1973, (in Japanese).

SASATANI, T., Source process of earthquakes as deduced from long-period seismic body waves. 2. Intermediate-depth earthquakes in the southern Kurile island arc, Geophys. Bull. Hokkaido Univ., 31, 59-81, 1974, (in Japanese).

Savage, J. C., The effect of rupture velocity upon seismic first motions, Bull. Seism. Soc. Amer., 55, 263-275, 1965.

SAVAGE, J. C., Radiation from a realistic model of faulting, Bull. Seism. Soc. Amer., 56, 577-592, 1966. 
Teng, T. L. and A. Ben-Menahem, Mechanism of deep earthquakes from spectrums of isolated body-wave signals, J. Geophys. Res., 70, 5157-5170, 1965.

WYsS, M., Stress estimates for south American shallow and deep earthquakes, J. Geophys. Res., 75, 1529-1544, 1970.

WYSs, M. and P. MolNAR, Source parameters of intermediate and deep focus earthquakes in the Tonga arc, Phys. Earth Planet. Interiors, 6, 279-292, 1972. 